\title{
How do Good and Bad News Impact Mood During the Covid-19 Pandemic? The Role of Similarity
}

Antonia Dörnemann ${ }^{1}$, Nika Boenisch ${ }^{1}$, Leonard Schommer ${ }^{1}$, Lara Winkelhorst ${ }^{1}$, and Tobias Wingen ${ }^{1,2}$

${ }^{1}$ Department of Psychology, University of Cologne, Germany

${ }^{2}$ Institute of General Practice and Family Medicine, University Hospital Bonn, University of Bonn, Germany

This article is now in press at the Journal of European Psychology Students (JEPS), where it has been peer-reviewed. It is the accepted version and may not replicate the final version published in this journal. It is not the copy of record and may differ from the final version.

Author Note. We thank Alexandra Fleischmann for her very helpful comments.

Correspondence concerning this article should be addressed to Antonia Dörnemann, Antonia.Doernemann@gmx.de.

The authors declare that they have no conflict of interest. 


\begin{abstract}
How do media reports about the Covid-19 pandemic influence our mood? Building on the social comparison theory, we predicted that reading negative news affecting a similar group would result in an impaired mood. In contrast, reading negative news about a dissimilar group should lead to improved mood. To test this, 150 undergraduate students read positive or negative news about the well-being of a similar or dissimilar group during the pandemic. As predicted, a mood assimilation effect occurred for similar groups, whilst a contrast effect occurred for a dissimilar group. The findings suggest that media reports can have a strong impact on mood. The direction of these effects, however, seems to depend strongly on social comparison processes. Keywords: media, group similarity, assimilation, contrast, mood, social comparison, Covid-19
\end{abstract}


How do Good and Bad News Impact Mood During the Covid-19 Pandemic? The Role of

\section{Similarity}

Humanity is currently facing a global pandemic and is going through a time of global crisis management. Individuals are affected by various interventions in their everyday life on different levels. Whilst some people are predominantly facing serious consequences associated with financial problems (Bonaccorsi et al., 2020), others rather suffer from social-distancing and emotional consequences such as discouragement and sadness (Đogaš et al., 2020). Meanwhile, there is already longitudinal evidence that the Covid-19 pandemic increased the anxiety rate among younger people (Kwong et al., 2020). Restrictions moreover might even cause a general worsening of mood (Terry, Parsons-Smith \& Terry, 2020). Investigating and understanding psychological factors that contribute to this development seems crucial. Employing a social comparison perspective, the present article contributes to this endeavor by focusing on the role of media reports.

Mass media, for example, television, newspapers, or social media, is of central importance during the COVID-19 pandemic (Casero-Ripollés, 2020; Gralinski \& Menachery, 2020). Recent research has shown that frequent use of media is associated with COVID-19 related social responsibility, trust, and adoption of protective measures, highlighting the important role of media during a pandemic (Ash, Galletta, Hangartner, Margalit, \& Pinna, 2020). But media does not only affect our behavior, but it might also impact people's well-being and could serve as a cardinal factor for influencing mood during the COVID-19 pandemic (Bao, Sun, Meng, Shier, \& Lu, 2020; Liu et al., 2020). Indeed, classic studies have shown that negatively valenced information can affect and worsen viewers' mood, even resulting in catastrophizing their worries (Johnston \& Davey, 1997). 
Studying mood is important, as mood is an elemental characteristic for the evaluation of one’s subjective well-being (Diener, Suh, Lucas, \& Smith, 1999; Yardley \& Rice, 1991). Following the conception of Diener (1984), subjective well-being consists of three components: positive affect, negative affect, and life satisfaction. Affect can be described as an umbrella term for mood and emotions (Barsade \& Gibson, 2007). Mood and emotions, however, are distinct phenomena (Lochner, 2016). Compared to mood, emotions are more intense and often directed to a specific stimulus. In contrast, mood is rather global, undirected, and more stable than emotions (Gray, Watson, Payne \& Cooper, 2001; Lochner, 2016). As mood has a considerable impact on positive and negative affect (Niven, 2013; Yardley \& Rice, 1991), it influences in turn people's subjective well-being. Thus, worsened mood (for example through the Covid-19 pandemic) can have serious psychological consequences. Mood instability is moreover a fundamental symptom of the development of a mental disorder especially for affective disorders (Gilbert, Allan, Nicholls, \& Olsen, 2005; Patel et al., 2015). Longitudinal studies researching psychological consequences of the COVID-19 pandemic have already found alarming results, by indicating a decrease in mental health, increased stress, higher anxiety, and depression rates (Huang \& Zhao, 2020; Kwong et al., 2020; Spoorthy, Pratapa, \& Mahant, 2020). It thus seems crucial to investigate the factors which influence people's mood during the pandemic.

In the context of a global pandemic, media can influence mood on a daily level by presenting different information about the COVID-19 pandemic and its consequences. For example, whilst some articles focus on the negative impacts of staying at home such as domestic violence (Bradbury-Jones \& Isham, 2020), others highlight positive consequences such as the lowered infection risk (Fadinger \& Schymik, 2020). Depending on the valence of the information, this could have different effects on mood. Indeed, exposure to positive or negative 
stimuli is often used as a method to induce positive or negative mood, respectively (Aslam et al., 2020; Gardner, 1985; Johnston \& Davey, 1997). However, former research on media effects during the COVID-19 pandemic focused predominantly on negative effects on mood. For example, the reading of news headlines about the Covid-19 pandemic mostly evoked negative sentiments (Aslam, Awan, Syed, Kashif, \& Parveen, 2020). Moreover, frequent exposure to social media during the Covid-19 pandemic was also correlated with difficulties concerning mental health (Gao et al., 2020). In the present article, we investigate whether reading news about the COVID-19 pandemic always has detrimental effects on mood or whether this depends on the valence of the media report. For example, it could be expected that positively valenced news articles lead to a positive mood and that negatively valenced news articles lead to a negative mode. Crucially, we examined whether the effect does not only depend on the valence of the news article (negative/positive) but also on the perceived similarity of the presented group in the article.

According to theories of social comparison, it seems likely that people's perceived similarity to a group would matter. People often compare themselves with others to make a judgment about their situation. Festinger (1954) emphasized the importance of social comparison and explained that people preferably compare themselves to people who are similar on the comparison dimension. Goethals and Darley (1977) extended this to similar others in general, that is, people usually compare to others that are similar on important dimensions (e.g., gender, age, race, etc.). In his Selective Accessibility Model (SAM), Mussweiler (2007) explained that perceived similarity to a given standard can lead to assimilation of one's judgment. According to SAM, people often compare themselves to others and engage in a first holistic assessment of similarities or differences. Based on the outcome of this first holistic assessment, people tend to 
assimilate their judgment to similar standards, whilst they contrast their judgment to dissimilar standards. As almost every stimulus can serve as a comparison standard (Mussweiler, 2007), social groups which are described in news articles may also serve as a comparison standard. Whilst Mussweiler (2007) focused on the impact of standard similarity on judgment, these findings could also be transferred to mood. If people tend to adapt their judgment to a standard, they feel similar to, they might also adapt their judgment about their mood to the mood state of the comparative standard. Indeed, studies have already shown that the mood of a comparative person can unconsciously be transferred to one's mood (Neumann \& Strack, 2000 These findings are also in line with the emotional contagion theory, which states that people often tend to adjust their emotional reactions to other people's emotional state (Gump \& Kulik, 1997). Whilst the emotional contagion theory could be invoked to explain assimilation effects, theories of social comparison, however, go beyond that and explain potential contrasting effects on mood.

Building on these theories, we predict that when reading about a specific group benefiting from the Covid-19 crisis (positive valence), this could increase people's mood if they feel similar to the respective group. Yet, if they feel dissimilar to this group, this positive news might even lead to a decreased mood. Our theorizing thus leads to the following hypotheses: We expected that participant's evaluation of their mood would depend on the valence of the article they read. Crucially, we expected an interaction between the valence of the article and the similarity of the described group.

H1: For participants reading about a similar group, we expected a decreased mood if the article has a negative valence, compared to an increased mood if the article has a positive valence (assimilation). 
H2: In contrast, for participants reading about a dissimilar group, we expected an increased mood if the article has a negative valence, compared to a decreased mood if the article has positive valence (contrasting).

\section{Methods}

The study was conducted as part of a university course at a large University. These studies are exempt from Institutional Review Board approval. The study was conducted consistent with the Declaration of Helsinki and all participants provided informed consent. The study was distributed online via the Qualtrics Survey Software. The research question and hypotheses were preregistered at https://aspredicted.org/blind.php?x=47fb2e. Furthermore, materials, data, and analyses are fully shared on the Open Science Framework (https://osf.io/jerpy).

\section{Participants}

Participants were recruited between May $30^{\text {th }}$ and June $3^{\text {rd }}, 2020$, when home office and online university courses were still common, and when restrictions concerning social activities and contact limitations were still in effect in Germany. We aimed to reach only undergraduate students as participants for the study to ensure that the target group meets our similarity criteria. Thus, only undergraduates with a minimum age of 18 years were included in the study. If participants indicated in the conscientiousness question that their data should not be used for analyses, we subsequently excluded those as well, in line with our preregistration. The survey was distributed via the institute's participant pool, as well as via social media groups, and was further shared and forwarded via participants' personal network to ensure the participation of a broad student community. Based on the power analysis software $G^{*}$ Power (Faul, Erdfelder, Buchner, \& Lang, 2009), we aimed at recruiting 128 participants to have an $80 \%$ power to detect 
a medium-sized effect, $(f=0.25, \alpha=.05)$. In case that we would manage to recruit more participants, we decided to also use the data of these additional participants for the analyses.

The initial sample consisted of 186 participants, of which two did not agree with the consent form and were thus excluded. We further excluded five individuals who were no undergraduates, four individuals who indicated to not use their data for our study, and 25 individuals who did not provide any information throughout the survey. Our final sample size consisted of $N=150$ individuals (age: $M=23.41$ years, $S D=5.69,72 \%$ female).

\section{Design}

The study employed a 2 x 2-between-subject-design with group similarity and valence as the two independent variables, and participant's mood as the dependent variable. Participants were randomly assigned to one of four conditions. Depending on the condition, participants read an article of either negative or positive valence, describing a subpopulation which they either felt similar to (students) or did not feel similar to (50+ aged full-time workers).

\section{Procedure}

Participants opened the survey via a Qualtrics link, which guided them through the study. First, they were presented with the consent form which they had to agree with if they wanted to further proceed with the study. Then, participants read an informative (fictional) text concerning a specific subpopulation (students vs. 50+ aged full-time workers), which either benefited or suffered from the present Covid-19 pandemic (positive vs. negative valence). For a translated version, see OSF materials. They further answered two manipulation checks concerning the independent variables to guarantee that the manipulation was successful. After reading the article, participants completed a questionnaire referring to their mood. Finally, they answered some information about their demographic background and were then debriefed. The entire 
session took about 25 minutes. Undergraduate students from the University of Cologne had the opportunity to receive compensation in terms of course credits for participating in the study.

\section{Materials}

The articles used for the manipulation were fictional and did not reflect the actual circumstances of each subpopulation. Only common positive and negative consequences of the Covid-19 pandemic were used and gathered for each condition. The fictional texts dealt with the influence and the consequences of the pandemic on social contacts, home studies/office, finances, and leisure activities. Depending on the condition, students or the $50+$ generation either were described as benefiting from the Covid-19 pandemic (e.g., "Studies showed that it is particularly easy for students to compensate for the loss of social contacts"), or as suffering from the pandemic (e.g., "Studies showed that students find it particularly difficult to compensate for the loss of social contacts"). We aimed to parallelize the sentence structure and keep the content consistent for each condition (see Table 1). However, some minor deviations could not be prevented to create a fluent and coherent text. For the original version of the fictional articles, please see the OSF materials.

The fictional texts also included two citations of fictional people who represented the given subpopulation (e.g., similar/positive "I can handle the current situation very well. I manage to use the free time productively and finally work on projects that I have put off for a long time. This makes me satisfied." Laura, 25 years). For the similar condition, we picked the names Laura and Jan representing the undergraduates, and Thomas and Sabine for the dissimilar condition personifying the elder generation. Laura and Jan have proven to be the most typical names for everyone who was born around 1995, whilst the names Thomas and Sabine seem to most typically for those people with the birth year 1965 (Bielefeld, 2003). 
Table 1

Excerpts of the fictional text visualizing parallelization of sentence structure.

\begin{tabular}{|c|c|}
\hline Condition & Excerpt \\
\hline Similar/ & For many students, studying at home is also a feasible solution. The flexibility \\
\hline Positive & $\begin{array}{l}\text { gained in this way proves to be advantageous in most cases. Being able to freely } \\
\text { schedule working hours is beneficial for the majority of students, as productivity } \\
\text { even increases at home. }\end{array}$ \\
\hline Similar/ & For many students, studying at home is hardly a feasible solution either. The \\
\hline Negative & $\begin{array}{l}\text { flexibility gained in this way proves to be disadvantageous in most cases. Being } \\
\text { forced to freely schedule working hours is a disadvantage for the majority of } \\
\text { students, as productivity decreases at home. }\end{array}$ \\
\hline $\begin{array}{l}\text { Dissimilar/ } \\
\text { Positive }\end{array}$ & $\begin{array}{l}\text { For many over } 50 \text { s, home office is also a feasible solution. The flexibility gained } \\
\text { in this way proves to be advantageous in most cases. Being able to freely } \\
\text { schedule working hours is a profit for the majority of the } 50+\text { generation, as } \\
\text { productivity even increases at home. }\end{array}$ \\
\hline Dissimilar/ & For many over 50s, home office is hardly a feasible solution either. The \\
\hline Negative & $\begin{array}{l}\text { flexibility gained in this way proves to be disadvantageous in most cases. Being } \\
\text { forced to freely schedule working hours is a disadvantage for the majority of the } \\
50+\text { generation, as productivity decreases at home. }\end{array}$ \\
\hline
\end{tabular}

\section{Measures}

To measure different aspects of mood, we decided to use an established mood scale assessing four happy mood items (happy, optimistic, joyful, content) and four sad mood items (melancholic, depressed, upset, sad). An exploratory factor analysis suggested that all items are part of the same factor (see OSF materials for details). We thus calculated participants' mood by averaging all items. To this end, negatively-coded items were reverse coded. We took and adapted the mood items from Sanchez, Vazquez, Gomez, and Joormann (2014), and translated them into German sentences (e.g., "I feel happy" or "I am upset", $\alpha=.90$ ). The Likert scale contained seven labeled anchor points, on which participants indicated how each given statement applied to their mood state. Anchor points ranged from 1 (= not at all) to 7 (= very much). 
To test whether the manipulation succeeded, we also employed two manipulation checks measuring our two independent variables group similarity by asking for their belongingness ("Do you feel that you belong to the group described?"), ranging from 1 (= not at all) to 7 (= very much) and valence ("How well does the group described in the text feel?"), ranging from 1 (= not well at all) to 7 (= very well).

Participants were further asked to provide information about their gender, age, and student status. Moreover, we exploratory assessed participants' life satisfaction and the impact of the Covid-19 pandemic on their life satisfaction by asking how much they agree with the following statement according to their current situation "I am satisfied with my life" ( $1=$ not at all, $7=$ very much $)$ and "The Covid-19 pandemic [ ...] my life satisfaction" $(1=$ badly deteriorated, $7=$ greatly improved). The item measuring life satisfaction was adapted from the Satisfaction with Life Scale (SWLS; Diener, Emmons, Larsen, and Griffin, 1985).

At the end of the survey, participants were asked how conscientiously they completed the study by asking how much effort and attention they had put into the study (e.g., "I put [...] effort into this study"; $1=$ almost no, $5=$ very much). We further asked participants if we should use their data ("In your honest opinion, should we use your data to analyze this survey?"). If they indicated not to do so, we consequently excluded them from analyses.

\section{Outline of the Analysis}

We tested our hypothesis with a between-subject two-factor ANOVA with group similarity and valence of the article as the independent variables and mood as the dependent variable. This ANOVA tested the predicted interaction between the group similarity and the valence of the article. Additionally, we conducted two follow-up $t$-tests comparing the similar- 
positive condition with the similar-negative condition, and secondly, the dissimilar-positive with the dissimilar-negative condition to detect whether these conditions differed significantly.

\section{Results}

\section{Manipulation Checks}

The manipulation checks suggested that the manipulations were successful. Participants who read an article about the well-being of students (similar condition) indicated to rather feel that they belong to the group $(M=4.90, S D=1.64)$, while participants, who read an article about the well-being of the elder 50+ generation (dissimilar condition), reported a lower belongingness to the group $(M=1.93, S D=1.31), t(148)=12.19, p<.001, d=1.99,95 \%-\mathrm{CI}[1.60,2.38]$.

Likewise, participants, who read an article about a subpopulation which increased their well-being (positive-valence condition) during the Covid-19 situation ascribed a better wellbeing to this group $(M=5.99, S D=0.95)$, than participants who read about a subpopulation which suffered from the pandemic (negative-valence condition) $(M=2.36, S D=1.18), t(148)=$ $20.85, p<.001, d=3.41,95 \%-\mathrm{CI}[2.90,3.91]$.

\footnotetext{
ANOVA

We conducted a 2 (similar vs. dissimilar) x 2 (positive vs. negative valence) betweensubjects ANOVA. As expected, neither significant main effects for group similarity, $F(1,146)=$ 2.60, $p=.109, \eta^{2} p=.02$, nor for valence, $F(1,146)=0.28, p=.601, \eta^{2} p<.01$, were detected. Importantly, and as predicted, the interaction between group similarity and valence was significant, $F(1,146)=6.16, p=.014, \eta^{2} p=.04$. This interaction suggests that depending on group similarity, participants differed in adapting their mood to the valence of the article. The results reflect a disordinal interaction pattern, see Figure 1.
} 


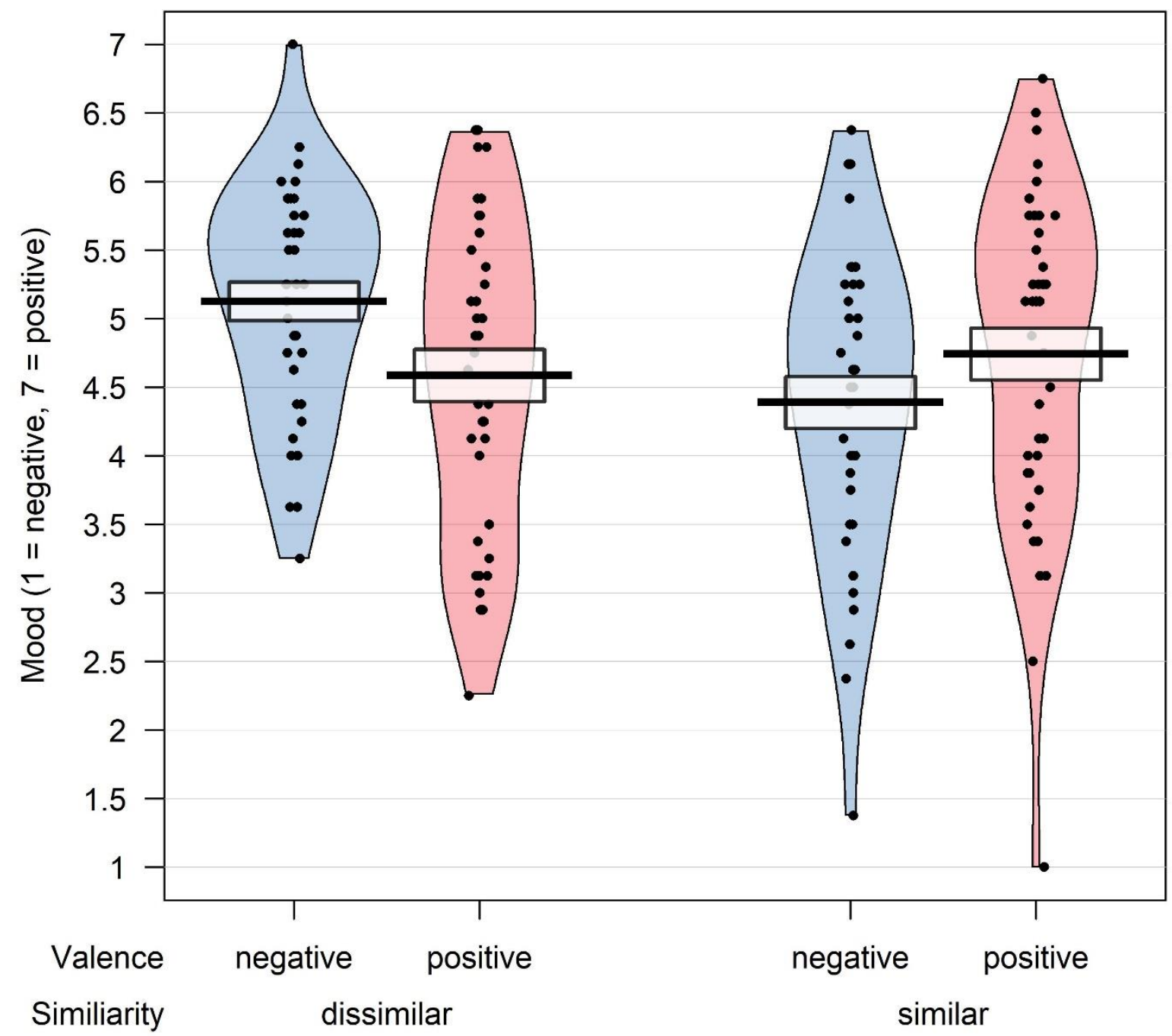

Figure 1: Pirate plot (Phillips, 2017) showing mood as a function of valence and similarity. The black dots represent the raw data, which is shown with smoothed densities indicating the distributions in each condition. The central tendency is the mean and the intervals represent two standard errors around the mean, comparable to commonly used bar plots. 


\section{Follow up $t$-tests}

To explore which conditions significantly differ, we further conducted two $t$-tests investigating the effect of valence in the two different similarity conditions. These $t$-tests followed directly from our predictions and hypotheses. We thus intended to preregister these two t-tests, but erroneously preregistered two different $t$-tests on the AsPredicted-platform. Please note that this reflects an innocent error in the preregistration and not a change in our analysis strategy.

The conducted $t$-tests revealed that participants tend to contrast their mood state to the valence of the article if a dissimilar group is addressed, $t(71)=-2.28, p=.026, d=0.54,95 \%$ $\mathrm{CI}[0.08,1.01]$. This means that when participants read an article in which the $50+$ generation was portrayed to benefit from the pandemic situation, participants indicated worse mood scores on average $(M=4.58, S D=1.15)$ than when this dissimilar group suffered from the pandemic $(M=5.13, S D=0.85)$. For the similar group condition, participants in the positive valence condition indicated higher mood values $(M=4.74, S D=1.21)$ than in the negative valence condition $(M=4.39, S D=1.13)$, however this effect did not reach statistical significance, $t(75)=$ $1.31, p=.194, d=0.30,95 \%-\mathrm{CI}[-0.76,0.16]$. Interestingly, participants did not only feel better, when they read an article about the older generation suffering, the dissimilar-negative condition even had the most positive scores on the mood scale across all conditions (see Table 2).

As participants in the dissimilar-negative valence condition revealed to have the highest mood scores, we were interested in whether these values significantly differ from the similarpositive condition. Thus, we further conducted an exploratory $t$-test between the dissimilarnegative and the similar-positive condition, which however suggested that participants in these two conditions did not significantly differ, $t(75)=-1.59, p=.116, d=0.37,95 \%$-CI[-0.09, 0.84]. 
Table 2

Descriptive Statistics Across Condition $(N=150)$

\begin{tabular}{lllll}
\hline Group Similarity & Valence & Mean & Std. Deviation & $N$ \\
\hline Similar & Positive & 4.74 & 1.21 & 41 \\
& Negative & 4.39 & 1.13 & 36 \\
\multirow{2}{*}{ Dissimilar } & Positive & 4.58 & 1.15 & 37 \\
& Negative & 5.13 & 0.85 & 36 \\
\hline
\end{tabular}

\section{Discussion}

The main aim of our study was to investigate how the valence of media articles influences the reader's mood in times of the Covid-19 pandemic. Furthermore, we predicted that this impact depends on the perceived similarity to the described group. In line with our predictions, the results indicate that media articles significantly influence mood during the Covid-19 pandemic. Importantly, a central factor that determines the direction of the influence seems to be the perceived similarity to the described group. Depending on whether they perceived the described group as similar or dissimilar, students varied in their mood adaptation. Whilst articles about a similar group led students to assimilate their mood, participants reading about a dissimilar group contrasted their mood state to the valence of the article, resulting in a significant valence $\mathrm{x}$ similarity-interaction.

Regarding what impact negative media articles concerning the Covid-19 pandemic could have on students, one could assume that students feel empathy and compassion for the older generation. However, the results of our study demonstrate the contrary, given that students indicated the best mood after reading a negatively valenced article, in which the older generation acutely suffered from the crisis. Participants in this condition showed similar increased mood 
scores to participants reading about a similar group with a positive valence. As a consequence, after reading about the dissimilar group's misery, students felt at least as good as participants reading about the high well-being of a similar group (similar/positive condition). These results could be explained by referring to the SAM (Mussweiler, 2007), which highlights assimilation and contrast as central processes of human judgment. However, which conclusion can be drawn from this contrast effect remains unclear. A possible inference could be that students feel happy about the negative well-being of the older generation. However, it could also reflect a feeling of relief that they themselves are not suffering from the pandemic as badly. These and other potential inferences require further research.

Our findings are also relevant for the doom scrolling phenomenon in online media (i.e., consuming a large quantity of negative online news at once, Paulsen \& Fuller, 2020). During the Covid-19 pandemic, the media primarily provided news that focused on the pandemic and its mostly negative consequences. Whilst the media can provide useful information about the pandemic such as health implications or prevention strategies (Ash et al., 2020; Liu et al, 2020), studies found that media consumption mainly predicts negative sentiments (Aslam et al., 2020; Gao et al., 2020; Johnston \& Davey, 1997). This could lead to the impression that excessive media consumption such as doom scrolling always negatively affects mood during the pandemic. Considering our results, this conclusion may be too simple. Given that participants indicated their highest subjective mood state when reading an article in which another dissimilar group suffered, negatively valenced articles might also positively contribute to people's mood, as long as the group is perceived as dissimilar. Thus, after consuming bad news, people might feel better, as articles often do not describe similar groups. In line with this argument, studies indicate that young adults tend to compare themselves to the elder generation to enhance their self-esteem 
(Harwood, 1999) or to maintain their own group's identity (Hewstone, Rubin, \& Willis, 2002).

Thus, media consumption of negative news might not necessarily be harmful but could also have positive effects on mood. As mood is a central indicator for subjective well-being (Yardley \& Rice, 1991), media use might thus also contribute positively to individuals' subjective wellbeing, even during a pandemic.

Instead of experiencing empathy and compassion for the elder generation, which is most severely affected by the pandemic, students contrasted their mood and indicated higher positive mood scores when this group was described as suffering. This apparent lack of empathy from the young generation seems worrying, since empathy for those who are most vulnerable may be a determining factor of Covid-19 protective behaviors such as vaccination willingness (Pfattheicher, Petersen, \& Böhm, 2020). Vaccination, however, can only contribute to herd immunity when a certain part of society is vaccinated (Plans-Rubió, 2012), highlighting the importance that also younger people take part, even though they usually suffer from less dramatic consequences from COVID-19 (Zhou et al., 2020). It thus seems crucial to investigate strategies on how to increase empathy with older people in the younger generation.

Despite these important implications, it is essential to consider the potential limitations of our study. Firstly, the texts of the four different conditions of our independent variables could not be completely parallelized because we had to implement some conceptual content-related deviations to reinforce a valid and convincing argumentation. Little discrepancies were necessary to find plausible arguments for the advantages and disadvantages of an online study program as well as for working from home. For example, for the most part, a students' financial situation is different from that of 50+ aged full-time workers, as students are often either financed by their parents or work in smaller part-time jobs to afford university and housing, and we thus wrote 
"Many students receive additional financial help and can continue to work on the side to pay their rent". A regular 50+ aged person, however, would probably have worked in a full-time job for at least 20 years and is dependent on a higher salary than students, and we thus wrote "Almost all over 50-year-olds can continue to work in the home office or request additional financial help". Therefore, both subpopulations differ in the level of financial security. For us, it seemed more appropriate to hold the four conditions qualitatively parallel (e.g., both groups facing no financial problems) instead of constantly using the exact same sentence structure.

Secondly, not only assimilation and contrast effects (Mussweiler, 2007) but rather demand effects (Orne, 1962) could have influenced our results. This would indicate that participants wanted to please the study conductors by acting according to the supposed hypothesis. Yet in our case, it is unlikely that the test subjects could predict our hypothesis as they were only assigned to one of the four between-subject conditions. Whilst they could have supposed "valence" as an independent variable, the second variable "group similarity" seemed to be less obvious, as the participants did not have insight into the other conditions, in which different groups are described.

A third limitation is that, for our research hypothesis, we had to choose a specific sample to manipulate similarity with the comparison standard. Therefore, we only recruited undergraduate students to ensure that a group of students would be perceived as similar, whereas a group of older people would be perceived as dissimilar by our participants. Nevertheless, the generalizability of our findings could be strengthened by additionally investigating the elder generation to see if their mood state is also sensitive to assimilation and contrast effects. Our results only indicate that the effect occurs for undergraduates, who represent just one of the two 
relevant groups described in the fictional articles. Consequently, our results are difficult to generalize, because we only examined one specific subpopulation.

This study thus provides important directions for future research, which could focus on the replication of our findings in an older population, as well as for other population groups beyond undergraduates and people older than 50 years. Additionally, a confirmatory replication study would be necessary, given that our $p$-values are close to .05 which increases the danger of false-positive significant findings in our work (Benjamin et al., 2017). Thus, a successful replication study could increase the trustworthiness of our findings (Anvari \& Lakens, 2018; Hendriks, Kienhues, \& Bromme, 2020; Wingen, Berkessel, \& Englich, 2020). Moreover, different samples and methods would be needed before generalizing our findings and drawing strong conclusions or advising policy.

In summary, the idea that bad news always negatively affects people's mood seems too simple. Our study found that mood assimilation is dependent on the similarity of the described group and can, consequently, lead to both, negative or positive mood after being confronted with an article about Covid-19 consequences. It is still highly alarming that younger people might emotionally benefit from reading about vulnerable people suffering from the consequences of the Covid-19 pandemic. This may reflect a lack of cooperation and empathy, especially among younger people. Given the importance of cohesion and empathy for other groups to successfully overcome a global crisis, addressing this issue as well as replicating and extending our work represents a fruitful endeavor for future research. 


\section{References}

Ash, E., Galletta, S., Hangartner, D., Margalit, Y., \& Pinna, M. (2020). The Effect of Fox News on Health Behavior During COVID-19. SSRN Electronic Journal, 1-56. doi:https://doi.org/10.2139/ssrn.3636762

Aslam, F., Awan, T. M., Syed, J. H., Kashif, A., \& Parveen, M. (2020). Sentiments and emotions evoked by news headlines of coronavirus disease (COVID-19) outbreak. Humanities and Social Sciences Communications, 7(1), 1-9. doi:https://doi.org/10.1057/s41599-0200523-3

Bao, Y., Sun, Y., Meng, S., Shier, J., \& Lu, L. (2020). 2019-nCoV epidemic: address mental health care to empower society. The Lancet, Volume 395(Issue 10224), e37-e38. doi:https://doi.org/10.1016/S0140-6736(20)30309-3

Barsade, S. G., \& Gibson, D. E. (2007). Why does affect matter in organizations?. Academy of management perspectives, 21(1), 36-59. doi:https://doi.org/10.5465/amp.2007.24286163

Benjamin, D. J., Berger, J. O., Johannesson, M., Nosek, B. A., Wagenmakers, E.-J., Berk, R., Bollen, K. A., Brembs, B., Brown, L., Camerer, C., Cesarini, D., Chambers, C. D., Clyde, M., Cook, T. D., De Boeck, P., Dienes, Z., Dreber, A., Easwaran, K., Efferson, C., ... Johnson, V. E. (2017). Redefine statistical significance. Nature Human Behaviour, 2(1), 6-10. doi:https://doi.org/10.1038/s41562-017-0189-z

Bielefeld, K. (2003). Beliebte (und seltene) Vornamen. Retrieved May $9^{\text {th }}$, 2020, from https://www.beliebte-vornamen.de

Bonaccorsi, G., Pierri, F., Cinelli, M., Flori, A., Galeazzi, A., Porcelli, F., Schmidt, A. L., Valensise, C. M., Scala, A., Quattrociocchi, W., \& Pammolli, F. (2020). Economic and social consequences of human mobility restrictions under COVID-19. Proceedings of the 
National Academy of Sciences, 117(27), 15530-15535.

doi:https://doi.org/10.1073/pnas.2007658117

Bradbury-Jones, C., \& Isham, L. (2020). The pandemic paradox: The consequences of COVID19 on domestic violence. Journal of Clinical Nursing, 29(13-14), 2047-2049. doi:https://doi.org/10.1111/jocn.15296

Casero-Ripolles, A. (2020). Impact of Covid-19 on the media system. Communicative and democratic consequences of news consumption during the outbreak. El Profesional de La Información, 29(2), 1-11. doi:https://doi.org/10.3145/epi.2020.mar.23

Diener, E. (1984). Subjective well-being. Psychological Bulletin, 95(3), 542-575. doi:https://doi.org/10.1037/0033-2909.95.3.542

Diener, E., Emmons, R. A., Larsen, R. J., \& Griffin, S. (1985). The Satisfaction With Life Scale. Journal of Personality Assessment, 49(1), 71-75. doi:https://doi.org/10.1207/s15327752jpa4901_13

Diener, E., Suh, E. M., Lucas, R. E., \& Smith, H. L. (1999). Subjective well-being: Three decades of progress. Psychological Bulletin, 125(2), 276-302. doi:https://doi.org/10.1037/0033-2909.125.2.276

Đogaš, Z., Lušić Kalcina, L., Pavlinac Dodig, I., Demirović, S., Madirazza, K., Valić, M., \& Pecotić, R. (2020). The effect of COVID-19 lockdown on lifestyle and mood in Croatian general population: a cross-sectional study. Croatian Medical Journal, 61(4), 309-318. doi:https://doi.org/10.3325/cmj.2020.61.309

Fadinger, H., \& Schymik, J. (2020). The costs and benefits of home office during the Covid-19 pandemic: Evidence from infections and an input-output model for Germany. Covid Economics, 9(24), 107-134. doi:https://doi.org/10.3886/E124902V2 
Farid Anvari \& Daniël Lakens (2018) The replicability crisis and public trust in psychological science, Comprehensive Results in Social Psychology, 3:3, 266-286, doi:https://doi.org/10.1080/23743603.2019.1684822

Faul, F., Erdfelder, E., Buchner, A., \& Lang, A.-G. (2009). Statistical power analyses using G*Power 3.1: Tests for correlation and regression analyses. Behavior Research Methods, 41(4), 1149-1160. doi:https://doi.org/10.3758/brm.41.4.1149

Festinger, L. (1954). A Theory of Social Comparison Processes. Human Relations, 7(2), 117140. doi:https://doi.org/10.1177/001872675400700202

Gao, J., Zheng, P., Jia, Y., Chen, H., Mao, Y., Chen, S., Wang, Y., Fu, H., \& Dai, J. (2020). Mental health problems and social media exposure during COVID-19 outbreak. PLOS ONE, 15(4), e0231924. doi:https://doi.org/10.1371/journal.pone.0231924

Gardner, M. P. (1985). Mood States and Consumer Behavior: A Critical Review. Journal of Consumer Research, 12(3), 281. doi:https://doi.org/10.1086/208516

Gilbert, P., Allan, S., Nicholls, W., \& Olsen, K. (2005). The assessment of psychological symptoms of patients referred to community mental health teams: distress, chronicity and life interference. Clinical Psychology \& Psychotherapy, 12(1), 10-27. doi:https://doi.org/10.1002/cpp.426

Goethals, G. R., \& Darley, J. M. (1977). Social comparison theory: An attributional approach. In J. M. Suls \& R. L. Miller (Eds.), Social comparison processes: Theoretical and empirical perspectives (pp. 259-278). Hemisphere.

Gralinski, L. E., \& Menachery, V. D. (2020). Return of the Coronavirus: 2019-nCoV. Viruses, 12(2), 135. doi:https://doi.org/10.3390/v12020135 
Gray, E. K., Watson, D., Payne, R., \& Cooper, C. (2001). Emotion, mood, and temperament: Similarities, differences, and a synthesis. Emotions at work: Theory, research and applications for management, 21-43.

Gump, B. B., \& Kulik, J. A. (1997). Stress, affiliation, and emotional contagion. Journal of personality and social psychology, 72(2), 305. doi:https://doi.org/10.1037/00223514.72.2.305

Harwood, J. (1999). Age identification, social identity gratifications, and television viewing. Journal of Broadcasting \& Electronic Media, 43(1), 123-136. doi:https://doi.org/10.1080/08838159909364479

Hendriks, F., Kienhues, D., \& Bromme, R. (2020). Replication crisis= trust crisis? The effect of successful vs failed replications on laypeople's trust in researchers and research. Public Understanding of Science, 29(3), 270-288.

doi:https://doi.org/10.1177/0963662520902383

Hewstone, M., Rubin, M., \& Willis, H. (2002). Intergroup Bias. Annual Review of Psychology, 53(1), 575-604. doi:https://doi.org/10.1146/annurev.psych.53.100901.135109

Huang, Y., \& Zhao, N. (2020). Generalized anxiety disorder, depressive symptoms and sleep quality during COVID-19 outbreak in China: a web-based cross-sectional survey. Psychiatry Research, 288, 112954. doi:https://doi.org/10.1016/j.psychres.2020.112954

Johnston, W. M., \& Davey, G. C. L. (1997). The psychological impact of negative TV news bulletins: The catastrophizing of personal worries. British Journal of Psychology, 88(1), 85-91. doi:https://doi.org/10.1111/j.2044-8295.1997.tb02622.x

Kwong, A. S. F., Pearson, R. M., Smith, D., Northstone, K., Lawlor, D. A., \& Timpson, N. J. (2020). Longitudinal evidence for persistent anxiety in young adults through COVID-19 
restrictions. Wellcome Open Research, 5, 195.

doi:https://doi.org/10.12688/wellcomeopenres.16206.1

Liu, Q., Zheng, Z., Zheng, J., Chen, Q., Liu, G., Chen, S., Chu, B., Zhu, H., Akinwunmi, B., Huang, J., Zhang, C. J. P., \& Ming, W.-K. (2020). Health Communication Through News Media During the Early Stage of the COVID-19 Outbreak in China: Digital Topic Modeling Approach. Journal of Medical Internet Research, 22(4), e19118. doi:https://doi.org/10.2196/19118

Lochner, K. (2016). Affect, mood, and emotions. In Successful Emotions (pp. 43-67). Springer, Wiesbaden. doi:https://doi.org/10.1007/978-3-658-12231-7_3

Mussweiler, T. (2007). Assimilation and Contrast as Comparison Effects: A Selective Accessibility Model. In J. Suls \& D. A. Stapel (Eds.), Assimilation and Contrast in Social Psychology (1st ed., pp. 165-185). Psychology Press. http://www.communicationcache.com/uploads/1/0/8/8/10887248/assimilation_and_contr ast_as_comparison_effects-_a_selective_accessibility_model.pdf

Neumann, R., \& Strack, F. (2000). "Mood contagion": The automatic transfer of mood between persons. Journal of Personality and Social Psychology, 79(2), 211-223. doi:https://doi.org/10.1037/0022-3514.79.2.211

Niven K. (2013) Affect. In: Gellman M.D., Turner J.R. (eds) Encyclopedia of Behavioral Medicine. Springer, New York, NY. doi:https://doi.org/10.1007/978-1-4419-10059_1088

Orne, M. T. (1962). On the social psychology of the psychological experiment: With particular reference to demand characteristics and their implications. American Psychologist, 17(11), 776-783. doi:https://doi.org/10.1037/h0043424 
Patel, R., Lloyd, T., Jackson, R., Ball, M., Shetty, H., Broadbent, M., Geddes, J. R., Stewart, R., McGuire, P., \& Taylor, M. (2015). Mood instability is a common feature of mental health disorders and is associated with poor clinical outcomes. BMJ Open, 5(5), e007504. doi:https://doi.org/10.1136/bmjopen-2014-007504

Paulsen, P., \& Fuller, D. (2020). Scrolling for data or doom during COVID-19? Canadian Journal of Public Health, 111(4), 490-491. doi:https://doi.org/10.17269/s41997-02000376-5

Phillips, N. (2017). Yarrr: A companion to the e-book “yarrr!: The pirate's guide to r". Retrieved from https://CRAN. R-project. org/package= yarrr.

Pfattheicher, S., Petersen, M. B., \& Böhm, R. (2020). Information about herd immunity and empathy promote COVID-19 vaccination intentions. doi:https://doi.org/10.31234/osf.io/wzu6k

Plans-Rubió, P. (2012). Evaluation of the establishment of herd immunity in the population by means of serological surveys and vaccination coverage. Human Vaccines \& Immunotherapeutics, 8(2), 184-188. doi:https://doi.org/10.4161/hv.18444

Sanchez, A., Vazquez, C., Gomez, D., \& Joormann, J. (2014). Gaze-fixation to happy faces predicts mood repair after a negative mood induction. Emotion, 14(1), 85-94. doi:https://doi.org/10.1037/a0034500

Spoorthy, M. S., Pratapa, S. K., \& Mahant, S. (2020). Mental health problems faced by healthcare workers due to the COVID-19 pandemic-A review. Asian Journal of Psychiatry, 51, 102119. doi:https://doi.org/10.1016/j.ajp.2020.102119 
Terry, P. C., Parsons-Smith, R. L., \& Terry, V. R. (2020). Mood Responses Associated With COVID-19 Restrictions. Frontiers in Psychology, 11, 1. doi:https://doi.org/10.3389/fpsyg.2020.589598

Wingen, T., Berkessel, J. B., \& Englich, B. (2020). No replication, no trust? How low replicability influences trust in psychology. Social Psychological and Personality Science, 11(4), 454-463. doi:https://doi.org/10.1177/1948550619877412

Yardley, J. K., \& Rice, R. W. (1991). The relationship between mood and subjective well-being. Social Indicators Research, 24(1), 101-111. doi:https://doi.org/10.1007/bf00292653

Zhou, F., Yu, T., Du, R., Fan, G., Liu, Y., Liu, Z., Xiang, J., Wang, Y., Song, B., Gu, X., Guan, L., Wei, Y., Li, H., Wu, X., Xu, J., Tu, S., Zhang, Y., Chen, H., \& Cao, B. (2020). Clinical course and risk factors for mortality of adult inpatients with COVID-19 in Wuhan, China: a retrospective cohort study. The Lancet, 395(10229), 1054-1062. doi:https://doi.org/10.1016/s0140-6736(20)30566-3 